\title{
D-region impact area of energetic electron precipitation during pulsating aurora
}

\author{
Emma Bland $^{1}$, Fasil Tesema ${ }^{1,2}$, and Noora Partamies ${ }^{1,2}$ \\ ${ }^{1}$ Department of Arctic Geophysics, University Centre in Svalbard, Longyearbyen, Norway \\ ${ }^{2}$ Birkeland Centre for Space Science, University of Bergen, Bergen, Norway
}

Correspondence: Emma Bland (emma.bland@unis.no)

Received: 6 August 2020 - Discussion started: 18 August 2020

Revised: 14 December 2020 - Accepted: 17 December 2020 - Published: 10 February 2021

\begin{abstract}
A total of 10 radars from the Super Dual Auroral Radar Network (SuperDARN) in Antarctica were used to estimate the spatial area over which energetic electron precipitation (EEP) impacts the D-region ionosphere during pulsating aurora (PsA) events. We use an all-sky camera (ASC) located at Syowa Station to confirm the presence of optical PsAs, and then we use the SuperDARN radars to detect high frequency (HF) radio attenuation caused by enhanced ionisation in the D-region ionosphere. The HF radio attenuation was identified visually by examining quick-look plots of the background HF radio noise and backscatter power from each radar. The EEP impact area was determined for 74 PsA events. Approximately one-third of these events have an EEP impact area that covers at least $12^{\circ}$ of magnetic latitude, and three-quarters cover at least $4^{\circ}$ of magnetic latitude. At the equatorward edge of the auroral oval, $44 \%$ of events have a magnetic local time extent of at least $7 \mathrm{~h}$, but this reduces to $17 \%$ at the poleward edge. We use these results to estimate the average size of the EEP impact area during PsAs, which could be used as a model input for determining the impact of PsA-related EEP on the atmospheric chemistry.
\end{abstract}

\section{Introduction}

Pulsating aurorae (PsAs) are diffuse auroral emissions which exhibit quasi-periodic brightness fluctuations of about 2-20 s (Lessard, 2012; Nishimura et al., 2020). They are commonly observed in the recovery phase of substorms, with the greatest occurrence rates in the early morning sector (Jones et al., 2011; Bland et al., 2019; Grono and Donovan, 2020). The energetic electron precipitation (EEP) that produces PsA is thought to arise from chorus wave activity, whereby electrons from the radiation belts are scattered into the atmospheric loss cone (Thorne et al., 2010; Kasahara et al., 2018). The precipitating electrons typically have energies up to the order of $10-100 \mathrm{keV}$, depositing their energy into the upper mesosphere/lower thermosphere region at approximately 70-120 km altitude (Fang et al., 2008; Turunen et al., 2009; Miyoshi et al., 2010; Tesema et al., 2020b). PsA-related electron density enhancements have been observed at altitudes as low as $68 \mathrm{~km}$, corresponding to electron energies of at least $200 \mathrm{keV}$ (Miyoshi et al., 2015; Turunen et al., 2016; Tesema et al., 2020a).

Due to their high occurrence rates, PsAs are thought to be a significant source of ionisation in the upper mesosphere/lower thermosphere region at high latitudes. Impact ionisation by EEP in this region leads to the production of odd-hydrogen $\left(\mathrm{HO}_{x}=\mathrm{OH}+\mathrm{HO}_{2}\right)$ and odd-nitrogen $\left(\mathrm{NO}_{x}=\right.$ $\mathrm{N}+\mathrm{NO}+\mathrm{NO}_{2}$ ) chemical species, which act as catalysts in ozone depletion reactions. Tesema et al. (2020a) used the 1D Sodankylä ion-neutral chemistry model (Verronen et al., 2005; Turunen et al., 2009) to show that a typical PsA energy spectrum applied for 120 min causes mesospheric oddoxygen depletion of $69 \%$. This significant chemical response indicates that PsA-related EEP may also need to be included in atmospheric/climate models, such as the Whole Atmosphere Community Climate Model (WACCM) (Marsh et al., 2007), to properly capture the long-term impact of EEP on natural climate variability. Currently, the EEP forcing in WACCM is described using an Ap-index-based parameterisation of particle flux measurements (van de Kamp et al., 2016) from the Polar Orbiting Environmental Satellite (POES). Although the actual particle flux measurements 
from POES would include the PsA-related EEP, the parameterisation is unlikely to capture the contribution from PsAs due to the poor correlation between PsA occurrence and geomagnetic indices (e.g. Partamies et al., 2017). Pulsating aurora may therefore represent a significant energy input to the atmosphere that is not currently captured in the forcing used for long-term modelling of natural climate variability.

To develop a more realistic EEP forcing for atmospheric/climate modelling applications that properly captures the contribution from PsAs, characteristics of PsAs, such as occurrence rates, durations, energy spectra and spatial coverage, need to be determined. PsA occurrence rates and event durations have been determined in several recent studies which used observations from all-sky cameras (ASCs). The median PsA event duration has been reported to be between 1.4 and $2.25 \mathrm{~h}$ (Jones et al., 2011; Partamies et al., 2017; Bland et al., 2019), and one event lasting $15 \mathrm{~h}$ was reported by Jones et al. (2013). Jones et al. (2011) and Grono and Donovan (2020) showed that PsAs are most common in the morning sector, with occurrence rates as high as $86 \%$ at around 03:30-06:00 magnetic local time (MLT). Since these occurrence rates were determined using optical data, the authors noted that the results are unreliable after about 06:00 MLT when the observation time is restricted by sunlight. Bland et al. (2019) made novel use of the Super Dual Auroral Radar Network (SuperDARN) radar at Syowa Station, Antarctica, to show that D-region ionisation associated with PsAs may continue up to about 10:00 MLT, when optical observations are not possible due to daylight.

Our current knowledge of the spatial distribution of PsAs comes from a series of studies that used the Time History of Events and Macroscale Interactions during Substorms (THEMIS) all-sky camera network in Canada (Donovan et al., 2006). THEMIS is well suited to studying the PsA spatial coverage due to its large combined field of view. Grono and Donovan (2019) used three THEMIS cameras and two meridian-scanning photometers to determine the upper and lower latitude boundaries of PsAs relative to the proton aurora location to identify the source region of the precipitating particle populations. Grono and Donovan (2020) then determined the occurrence probability of PsAs as a function of magnetic latitude and MLT. These studies made a distinction between different types of PsAs - amorphous PsAs (APA), patchy PsAs (PPA), and patchy aurora (PA) (see also Grono and Donovan, 2018) - based mainly on the spatial extent and stability of the pulsations and their motion with the convection. These different PsA types were shown to have different source regions and occurrence distributions. APA was found to have the highest occurrence rate and the widest spatial distribution in both latitude and MLT. APA was the dominant PsA type observed in the pre-midnight sector, whereas all three types were detected in the early morning sector. Yang et al. (2019) reported that APA were associated with stronger cosmic noise absorption compared to PPA for a fixed auroral brightness. In a larger study using incoherent scatter radar and imaging riometer (relative ionospheric opacity meter) data, Tesema et al. (2020b) showed that the electron density enhancement below $100 \mathrm{~km}$ altitude was greatest for PPAand PA-type events, indicating that these precipitating particle populations have higher energies on average compared to APA. Although these conclusions are not consistent, they show that it may be important to distinguish between the different types of PsAs when characterising the middle atmospheric response to EEP.

Grono and Donovan $(2019,2020)$ provided new information about the occurrence probability of APA, PPA, and PA at different latitudes and MLTs. These results, however, do not provide information about the latitudinal and MLT extent of individual events. This type of spatial coverage information is important for developing a realistic model input. A single PsA event reported by Jones et al. (2013) spanned more than $10 \mathrm{~h}$ of MLT at its maximum, but this is probably much wider than average. Since optical observations of PsAs are possible only during periods of dark, clear skies, it is very difficult to obtain a data set that is large enough to estimate the statistical spatial coverage of PsAs. Furthermore, cameras provide no information about the precipitating particle energy spectrum, or, at best, they provide very limited information, such as the peak emission height (e.g. Partamies et al., 2017). This type of information is important for determining whether a noticeable atmospheric chemical response will occur. Tesema et al. (2020a) developed statistical energy spectra for PsAs by combining satellite measurements from 253 events and then used these results to model the atmospheric chemical response to different levels of forcing. They showed that not all PsAs have sufficient energy to produce a measurable chemical response. Therefore, PsA occurrence rates and spatial coverage information determined from optical data alone may overestimate the forcing applied to the mesosphere-lower thermosphere region and the resulting chemical response.

The purpose of this study is to estimate the typical area over which PsA-related EEP has sufficient energy to reach mesosphere-lower thermosphere altitudes $(\sim 10-200 \mathrm{keV})$ and, hence, produce a chemical response. We shall refer to this area as the EEP impact area. To perform this estimate, we use the fact that this higher energy precipitation causes enhanced ionisation in the D-region ionosphere, which in turn attenuates high frequency (HF) radio waves. This attenuation can be detected using SuperDARN HF radars, as previously shown by Bland et al. (2019). In this study, we build upon this work by using 10 SuperDARN radars in Antarctica to estimate the EEP impact area for different types of PsAs.

\section{Instrumentation}

SuperDARN is a global network of 36 HF radars primarily designed for studying high-latitude plasma convection (Greenwald et al., 1995; Chisham et al., 2007; Nishitani 
et al., 2019). Recently, the radars have also been used to detect $\mathrm{HF}$ radio attenuation during shortwave fadeout events (Watanabe and Nishitani, 2013; Berngardt et al., 2018; Chakraborty et al., 2018; Fiori et al., 2018), polar cap absorption events (Bland et al., 2018; Chakraborty et al., 2019), and auroral absorption events including PsAs (Bland et al., 2019). HF radio attenuation events are identified in the $\mathrm{Su}-$ perDARN radar data as periods of reduced backscatter power combined with a reduction in the background radio noise. The reduced backscatter power is caused by the attenuation of the transmitted radio waves in the ionosphere, which often reduces the signal strength to below the detection threshold (e.g. Bland et al., 2018). The reduced background noise levels are caused by the attenuation of the background HF radio noise at the radar operating frequency. At the standard SuperDARN operating frequencies of 8-20 MHz, this background radio noise is produced mainly by lightning activity and propagates around the globe via ionospheric reflections. The noise measurements can be used to estimate the attenuation in decibels relative to a radar-specific quiet day curve, using an approach analogous to riometry (Bland et al., 2018; Berngardt, 2020). However, due to the high variability in the noise at the SuperDARN operating frequencies, producing quiet day curves is not straightforward, and the methodology is still being developed (Berngardt, 2020). Therefore, in this work, we adopt a more qualitative approach based on visual identification of $\mathrm{HF}$ attenuation events in quick-look plots.

In this study we have used 10 SuperDARN radars located in Antarctica and also an all-sky colour digital camera located at Syowa Station. The locations of the radars and the all-sky camera are shown in Fig. 1. The grey shading and magnetic local time (MLT) contours in Fig. 1 relate to the example event described Sect. 3. The red circle shows the ASC field of view projected to $100 \mathrm{~km}$ height. The radar fields of view are shown in black, and beam 5 for each radar is shaded yellow. For simplicity, we show only the near-range field of view of each radar (180-600 km in range), which is the approximate area in which the transmitted radio waves pass through the D-region ionosphere. This estimate is based on the vertical extent of the radars' antenna radiation patterns extending from roughly 10 to $50^{\circ}$ from the horizontal (e.g. Milan et al., 1997). Each radar's total field of view extends to over $3500 \mathrm{~km}$ in range, creating significant overlap between the fields of view, which is useful for measuring the F-region ionospheric convection (e.g. Nishitani et al., 2019, Fig. 1b). Each SuperDARN radar consists of a linear array of logperiodic or twin-terminated folded dipole antennas which are phased electronically to produce a beam which can be steered in 16 different azimuthal directions. This beam is narrow in azimuth $\left(\sim 3.5^{\circ}\right)$ but has a wide vertical extent $\left(\sim 40^{\circ}\right)$. The 16 beams are scanned sequentially every minute, with a $\sim 3 \mathrm{~s}$ integration time for each beam.

SuperDARN radars detect coherent backscatter from electron density structures in the E-region and F-region ionospheres and also from the ground, following reflection in the ionosphere. The Southern Hemisphere SuperDARN radars were chosen for this study because they generally detect larger amounts of backscatter on the nightside compared to the Northern Hemisphere radars. This is probably due to the favourable orientation of the geomagnetic field relative to the radar look directions and geographic latitudes. The nearcontinuous presence of backscatter on the nightside for most Antarctic radars makes it straightforward to identify periods of reduced backscatter power caused by HF radio attenuation. An example of this procedure is given in Sect. 3 . Note that the three mid-latitude SuperDARN radars located in Australia/New Zealand were not included in this study, due to their very large spatial separation from the radars in Antarctica, so they are not shown in Fig. 1.

The camera located at Syowa Station is a colour digital camera fitted with a $8 \mathrm{~mm} \mathrm{f} / 2.8$ fisheye lens. The imaging season lasts from April to October, and the camera is programmed to capture images automatically whenever the Sun is more than $12^{\circ}$ below the horizon. Exposure times are a few seconds, and the image cadence varies from about 6 to 30 s. Daily keogram (quick-look) plots are constructed by taking a magnetic north-south slice through the all-sky image and then placing these slices on a time axis. Similarly, an ewogram (east-west keogram) can be constructed using a magnetic east-west slice. PsAs can be readily identified in these plots as patchy auroral displays (e.g. Jones et al., 2013; Partamies et al., 2017; Yang et al., 2017), but the original allsky images are normally required to determine the PsA type (APA, PPA, and PA).

\section{Example event - 14 June 2015}

Our method for visually identifying signatures of HF radio attenuation is illustrated using Fig. 2. The $12 \mathrm{~h}$ time interval shown commenced at 18:00 universal time (UT) on 13 June 2015. This figure shows the magnetic north-south keogram plot for the all-sky camera at Syowa Station and the background noise and power measurements for each radar with available data. The panels are arranged in order of magnetic latitude, but it should be noted that the radars are located over a wide range of longitudes (see Fig. 1). The keograms are identical in both columns, with magnetic south at the top. The yellow vertical lines in the keogram plots indicate the onset and end times of a PsA event observed over Syowa Station on 14 June 2015. This is an APA event which occurred in the recovery phase of a substorm. There is a second APA event in this time interval which commences at 04:20 UT, but for the purposes of illustrating our event selection, we will focus on the first event at 00:40-02:20 UT. No data were available from either the Falkland Islands (FIR) radar or the South African National Antarctic Expedition (SAN) radar during this time interval, so they are not included in the figure.

The first column of Fig. 2 shows the background noise measurements from each beam of each radar. The noise data 


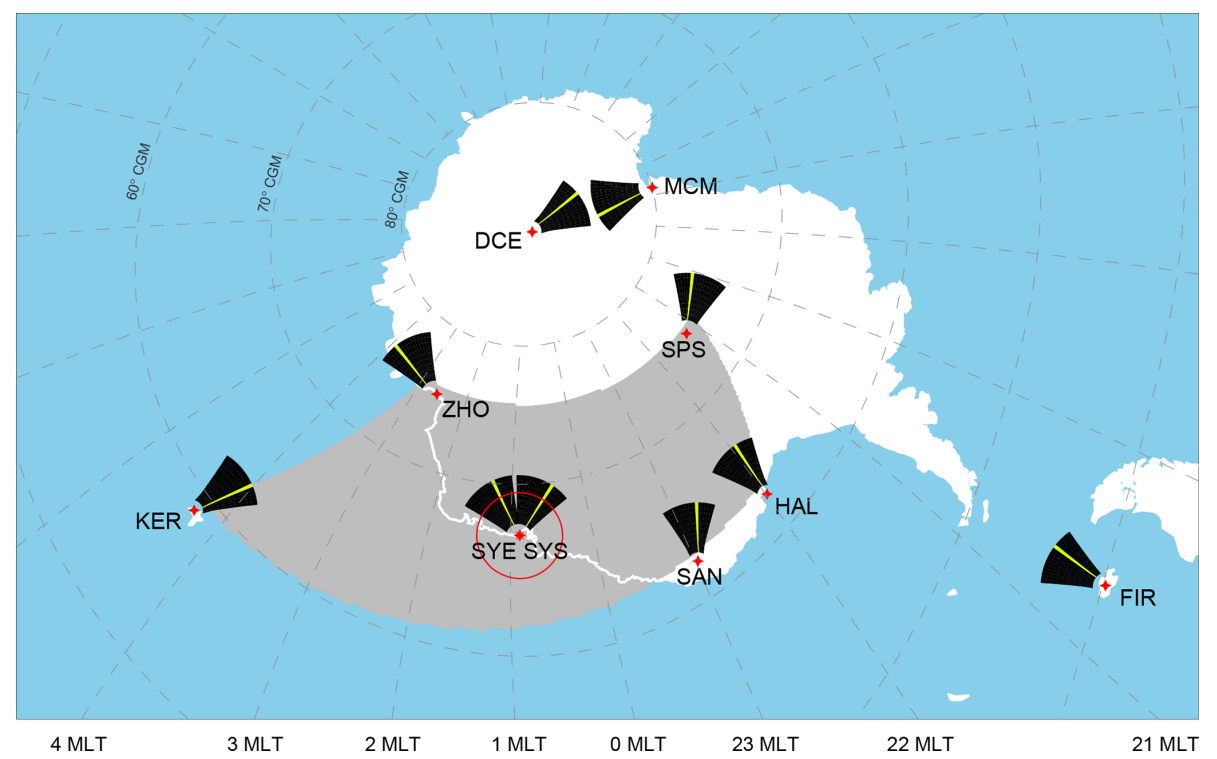

Figure 1. Locations and fields of view of the SuperDARN radars and all-sky camera used in this study. Instrument locations are shown by red symbols. The red circle indicates the camera field of view, and the black shading indicates the radar fields of view. The position of beam 5 for each radar is shaded yellow. Only the first $600 \mathrm{~km}$ of the radar fields of view are shown, which is the area in which the radio waves are expected to pass through the D-region ionosphere. The grey shading shows the spatial coverage of the energetic electron precipitation impact area for the example pulsating aurora event on 14 June 2015, 00:40-02:20 UT. Dashed grey lines indicate corrected geomagnetic (CGM) latitude and magnetic local time (MLT) contours.

have been binned into $10 \mathrm{~min}$ intervals and averaged separately in each bin to remove spikes. These data have arbitrary units, and the colour scales were chosen to best match the dynamic range of the noise measurements from each radar. The colour scales contain 256 colours and are saturated at the top end in order to emphasise the low-power features. For most radars there is some variation in the noise levels between different beams, which may arise from real spatial variations in the atmospheric noise production and ionospheric propagation conditions or differences in beamforming across the radar field of view. For this work, we are not interested in the absolute values of the background noise. Instead, we look for sudden changes in the background noise over the entire field of view which indicate that the HF radio noise has been attenuated in response to enhanced D-region ionisation. For the example event, reduced background noise levels during the PsA event are observed for six out of the eight radars shown, as indicated by the black vertical lines.

To justify that the reduced background noise measured at the six radar sites was indeed caused by enhanced D-region ionisation, we also study the backscatter power measured by each radar. These measurements are shown in the right column of Fig. 2. Each panel shows the raw power levels measured in each $45 \mathrm{~km}$ range gate along beam 5 . The raw power measurements also have arbitrary units and are displayed on a logarithmic scale. High power values observed across several range gates, and lasting from several minutes to hours, indicate coherent backscatter returning to the radar from ionospheric electron density irregularities or from the ground. The yellow vertical lines on these plots indicate the time periods for which the background noise was attenuated (determined from the left panel). During these time periods, the backscatter returns from all six radars have reduced power or are completely suppressed. This indicates that the radio waves transmitted by the radar have been attenuated. This combination of reduced background noise and reduced backscatter power is strong evidence that the D-region electron density has been enhanced near the radar site (Bland et al., 2018), and we use these two signatures together in our event selection for this study.

For the example shown in Fig. 2, there are two radars that did not detect a clear attenuation signature during the PsA event. These are the McMurdo (MCM) and Dome C East (DCE) radars, located at 80 and $89^{\circ}$ corrected geomagnetic (CGM) latitude, respectively. For these radars, there is neither a clear decrease in the background noise level nor a reduction in the backscatter power. Note that the background noise at MCM does decrease close to the event onset time. This, however, is accompanied by an increase in the echo power, which indicates that the transmitted radio waves were not strongly attenuated in the ionosphere. Therefore, the reduced noise at MCM is probably related to the normal diurnal variation in the background noise at the radar site rather than being a response to energetic particle precipitation.

Based on the information in Fig. 2, we can now make a rough estimate of the spatial coverage of the EEP impact 
area for this PsA event. This area is shown by the grey shading in Fig. 1, which is the region bounded by the six radars that detected the event. This area actually represents the minimum EEP impact area for this event. The poleward edge of the EEP impact area extends to at least $75^{\circ}$ CGM latitude, where both the South Pole Station (SPS) and Zhongshan (ZHO) radars detected attenuation, but it does not extend as far as the MCM radar at $80^{\circ} \mathrm{CGM}$ latitude. At the event onset, the SPS and ZHO fields of view were located at 20-21 and 03-04 MLT, respectively, indicating an instantaneous MLT extent of about $7 \mathrm{~h}$. A similar MLT extent at the equatorward edge of the EEP impact area is inferred from the Halley (HAL) and Kerguelen (KER) radar pair, extending from $\sim 22-04$ MLT at the event onset. Since the event was detected at the KER radar site, we can conclude that the equatorward edge of the EEP impact area extends at least as far as $60^{\circ} \mathrm{CGM}$ latitude in the morning sector. No data were available from the SAN or FIR radars for this event, so we cannot determine whether the EEP impact area extends to the locations of these radars.

It is worth commenting briefly on the nature of background radio noise measurements from SuperDARN radars. The background noise consists of (1) natural atmospheric radio noise, (2) anthropogenic noise produced by electrical and electronic equipment near the radar site, and (3) internal noise in the radar receiver system. The short- and longterm variability in the background noise depends on the relative contribution of these three sources to the total noise level. EEP-related attenuation signatures are easiest to identify when the background radio noise exhibits a smooth diurnal variation in the absence of any D-region enhancement. In Fig. 2, we observe this smooth noise variation in the DCE, MCM, ZHO, SPS, and Syowa East (SYE) data, and the sudden reduction in the background noise at the onset of PsAs stands out clearly against the slowly varying background. This diurnal variation in the noise is controlled by the global atmospheric noise production and ionospheric propagation conditions. In contrast, the noise measurements from the Halley (HAL) radar are highly variable from one $10 \mathrm{~min}$ time bin to the next and also between neighbouring beams, which might arise from either internal receiver noise or anthropogenic noise near the radar site. This variability in the noise measurements at Halley makes the visual identification of HF attenuation signatures more difficult. For this radar, the echo loss from 00:30-02:30 UT is clear (right column of Fig. 2), so we rely more heavily on this parameter to determine whether any HF attenuation has occurred. This type of variability in the background noise measurements for some radars is a key reason for adopting qualitative event selection criteria in this study, as some judgement regarding the usability of the data is required in each case.

\section{Event identification for statistical study}

To select PsA events for our statistical study of the EEP impact area, we began with a list of 102 optical PsA events identified visually in keogram plots from the all-sky camera at Syowa Station. This same event list was used by Bland et al. (2019) to determine PsA occurrence rates and durations using the SYE SuperDARN radar paired with the all-sky camera data. This event list excludes all solar proton events based on the threshold of 10 protons $\mathrm{cm}^{-2} \mathrm{sr}^{-1} \mathrm{~s}^{-1}$ with energies above $10 \mathrm{MeV}$. Excluding these events removes most of the effects of polar cap absorption from this study. The optical PsA events were classified as APA, PPA, or PA by visually studying the keogram and ewogram plots and also the $10 \mathrm{~s}$ cadence all-sky images for each event. The pulsating auroral structures that we used to distinguish between the different types are described in detail by Grono and Donovan (2018) and Yang et al. (2019). APA are identified as transient pulsating emissions with no persistent structure or sense of average motion. In contrast, PPA and PA consist of quasi-stable auroral patches that last for tens of minutes and can be tracked across the camera field of view. For PA, pulsations are observed only within a small portion of the emission, such as near the edges, whereas for PPA the pulsations are observed over a much larger area. For the 56 events in our list, one dominant type of PsA was observed throughout the whole event. For the remaining 18 events, the dominant type of PsA changed part-way through the event. For these events, we classified them based on the first type of PsA that was observed. There were only three events during which PA were observed, and in all cases, the PA were preceded by APA so they were classified as APA. Note that our PsA classifications apply only to Syowa Station as we cannot determine the PsA type from the radar data. Due to this limitation, this study is designed to detect periods of enhanced D-region ionisation that occur simultaneously with different types of optical PsAs observed at Syowa Station.

Quick-look plots similar to Fig. 2 were produced for each PsA event in the list. For each radar, we determined whether the background noise level and the echo power had been attenuated based on a visual inspection of the data. Often there was some uncertainty about whether a given radar had (or had not) detected an EEP signature. In particular, for some radars it was unclear whether the background noise had decreased (e.g. Fig. 2; HAL and KER radars). To capture this uncertainty, the attenuation for each radar was classified as clearly observed/not observed or probably observed/not observed. If we could not determine the presence or absence of an attenuation signature either way for a given event, then that radar was excluded from the analysis. For an event to be included in this study, we required that at least one radar in addition to the Syowa Station instrumentation had data available with sufficient quality to determine whether an attenuation signature was present. The final event list contained 74 events detected during the 2011, 2013, and 2015 Antarc- 

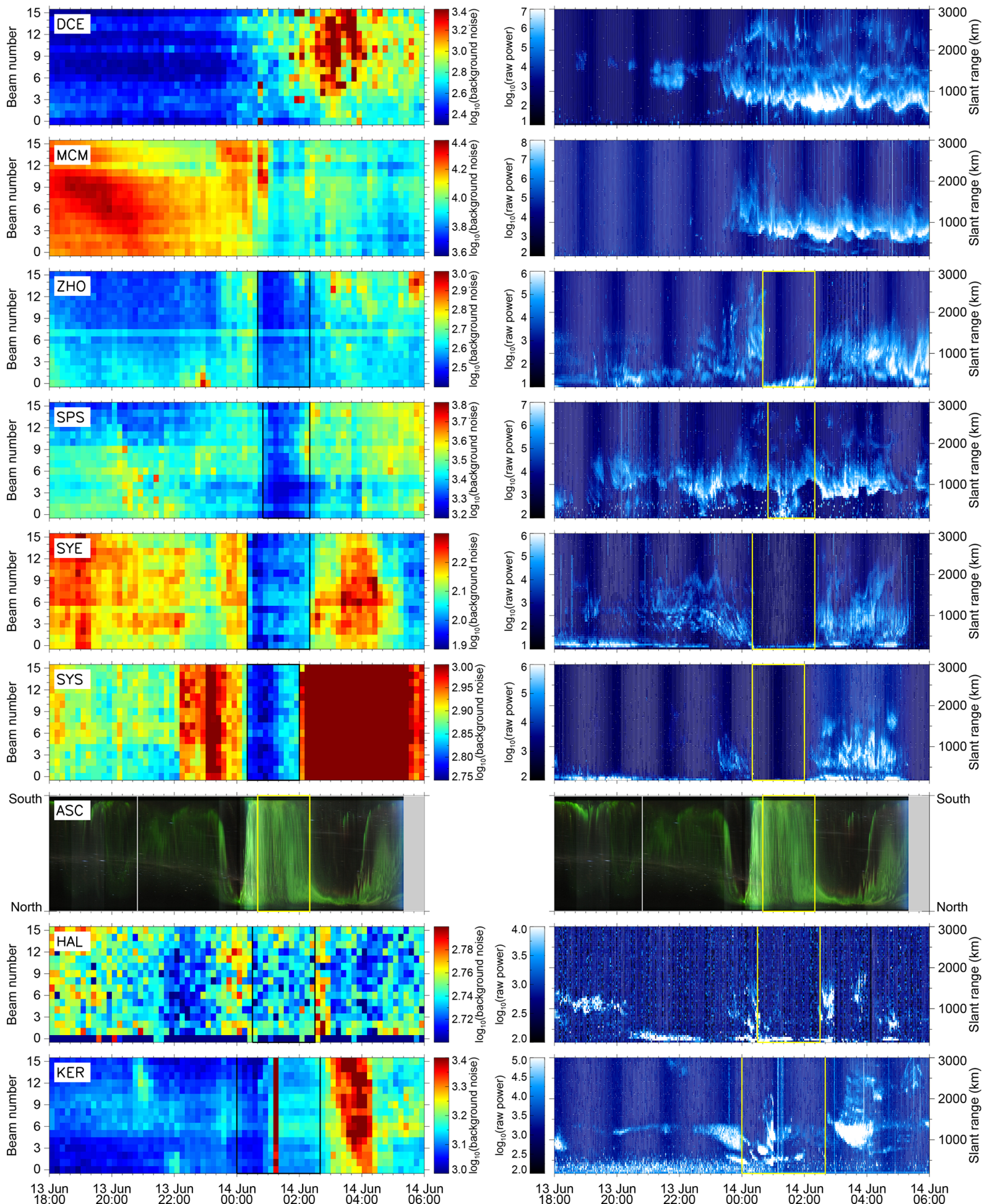

Figure 2. Quick-look plots showing the background radio noise (left) and raw echo power (right) parameters for eight SuperDARN radars from 13-14 June 2015. The magnetic north-south keogram from the all-sky camera (ASC) at Syowa Station is also shown in both columns. The event start and end times are marked using black/yellow vertical lines. 
tic winter seasons. For each event we recorded the following information:

- The availability of data from each radar;

- The start time and end time of the attenuation at each radar site (if observed);

- A classification of our uncertainty regarding whether or not any HF attenuation had occurred at each radar site.

In most cases, the onset times for each radar that detected the event are within $30 \mathrm{~min}$ of the onset times recorded for the SYE radar. For a few events, the onset times at ZHO, KER, or SPS are delayed 1-3h after the onset at SYE, but there is still considerable temporal overlap between the two sites. This might indicate a latitudinal expansion of the EEP impact area as the event evolves. Similarly, there are three events during which the HAL or KER radars detected attenuation more than $1 \mathrm{~h}$ before the onset at SYE, which might indicate that the particle precipitation began at lower latitudes and later expanded over Syowa Station.

In this study, we have used the all-sky camera at Syowa Station to determine the presence of optical PsAs. Since HF attenuation will occur in response to any process that enhances the D-region ionisation, we cannot confirm that the attenuation signatures observed by the radars were caused by PsAs specifically. For example, the attenuation observed by the SYE and Syowa South (SYS) radars in Fig. 2 commences at substorm onset at 00:20 UT, about 20 min before optical PsAs are visible in the keogram. This is very typical since PsAs are frequently observed in the substorm recovery phase, so the onset times determined from the radar data will often be 10-30 min earlier than the onset of optical PsAs (Bland et al., 2019). To increase the chances that the attenuation signatures at all radar sites are due to PsA-related $\mathrm{EEP}$, we require that the attenuation observed by any individual radar lasts for at least $1 \mathrm{~h}$ to qualify as a positive event identification at that site. Since substorm expansion phases are relatively short (Juusola et al., 2011; Partamies et al., 2013), this criterion should eliminate brief attenuation enhancements during substorm expansion phases that are not accompanied by PsAs in the recovery phase.

\section{Results}

Figure 3 is a bar graph showing the number of events observed and not observed by each radar. Colour coding is used to represent our uncertainty in determining whether any $\mathrm{HF}$ attenuation had occurred. The ASC is also included in this plot, with all 74 events clearly present. The data presented in both panels are identical, but the radars/ASC are ordered by magnetic latitude in Fig. 3a and by magnetic longitude in Fig. 3b. The SYE and SYS radars detected attenuation during all events for which data were available (74 and 63 events, respectively). For the SYE radar, five of these events included
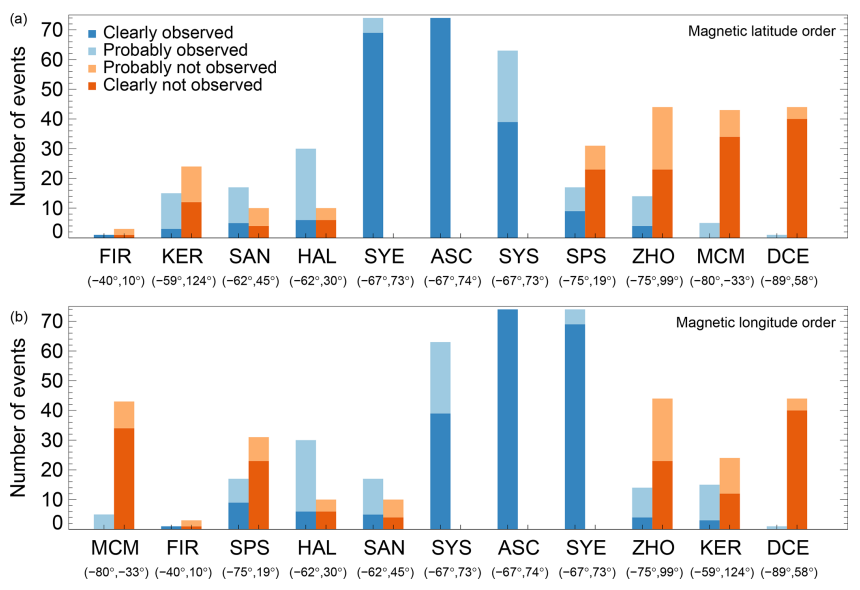

Figure 3. Number of events observed and not observed by each radar and the ASC. The instruments are sorted by magnetic latitude in (a) and by magnetic longitude in (b), except for DCE. Corrected geomagnetic coordinates are given in parentheses.

some evidence of HF attenuation, but this signature was less clear compared to the other events. For the KER and HAL radars, most of the positive and negative identifications of $\mathrm{HF}$ attenuation were uncertain due to the variability in the background noise and lower backscatter occurrence for these radars, similar to Fig. 2. The MCM and DCE radars rarely detect any attenuation during the PsA events. These two radars had good data availability, high echo occurrence, and the background noise exhibits smooth diurnal variations, so we conclude that the EEP impact area rarely extends to these latitudes. The lowest latitude radar, FIR, had very limited data availability, so it is not possible to draw conclusions about the EEP response at that location.

To obtain a general overview of the spatial coverage of the PsA events, it is helpful to first consider only those events that had data available from most of the radars. Therefore, we now take the subset of events with data available from at least five of the following six radars: HAL, KER, SAN, SPS, SYE, and ZHO. These radars cover the spatial region extending from 59 to $75^{\circ}$ magnetic latitude over a $\sim 100^{\circ}$-wide magnetic longitudinal sector. The DCE and MCM radars are not included in this list because the event-detection rate at these sites was close to zero. The FIR radar was also excluded due to the low data availability.

In total, there were 17 APA and 10 PPA events with data available from at least five of the six radars listed above, and the EEP impact area for these events is shown in Figs. 4 and 5 , respectively. For events where the PsA type changed during the event, we grouped the events according to the PsA type observed at the event onset. The events have been sorted and numbered according to the magnetic local time of the event onset at SYE. The red symbols are used to indicate our uncertainty in whether attenuation occurred or did not occur at each radar site. The light grey shading shows the region 

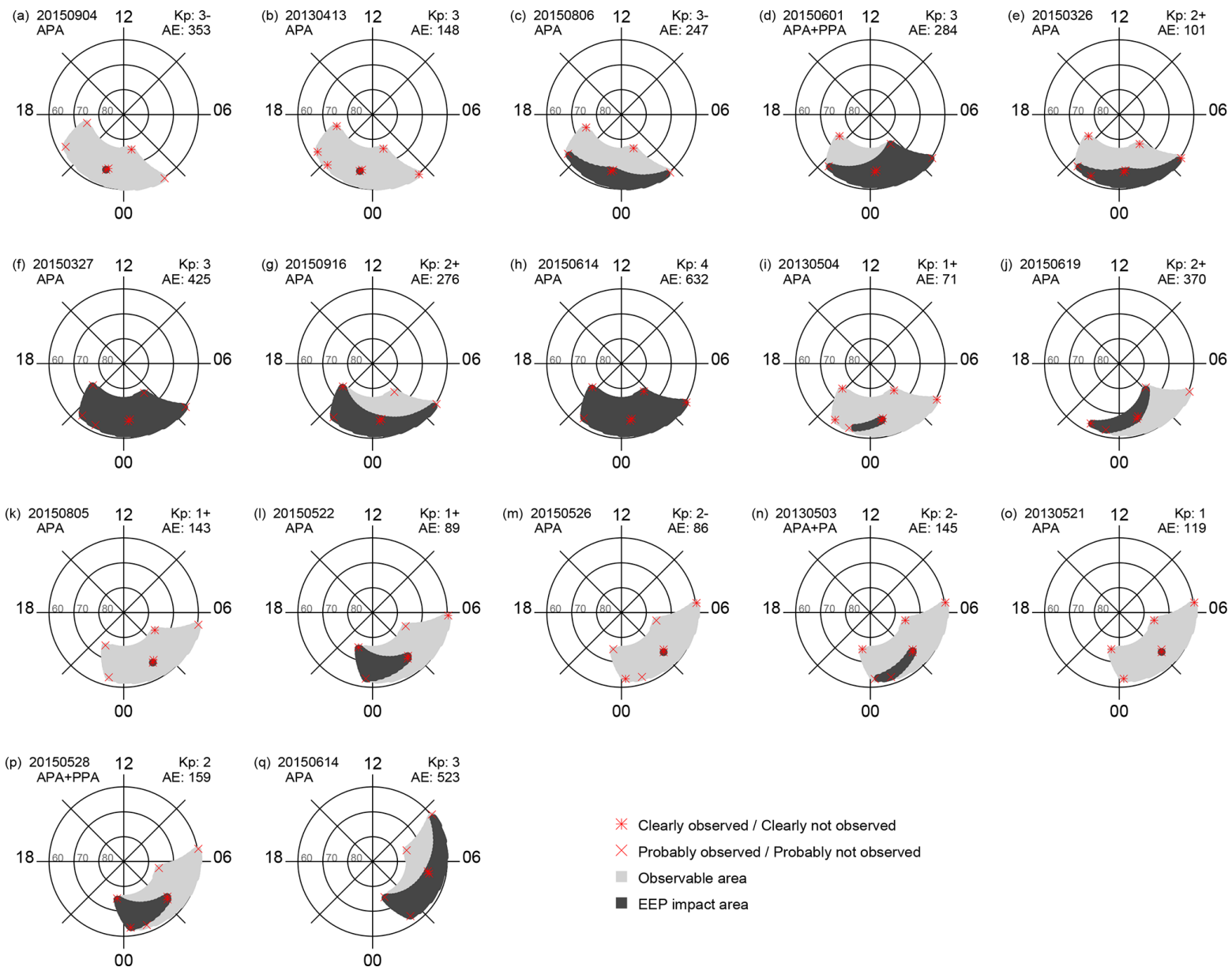

* Clearly observed / Clearly not observed
$\times$ Probably observed / Probably not observed
Observable area

EEP impact area

Figure 4. EEP impact area for amorphous pulsating aurora (APA) events with data available from at least five radars. The dark grey shading shows the EEP impact area, defined as the latitude/MLT region bounded by all radars that detected attenuation during that event (see text for details). The light grey shading shows the region bounded by the radars that did not detect any attenuation. Red symbols are used to indicate our uncertainty in determining whether any attenuation had occurred.
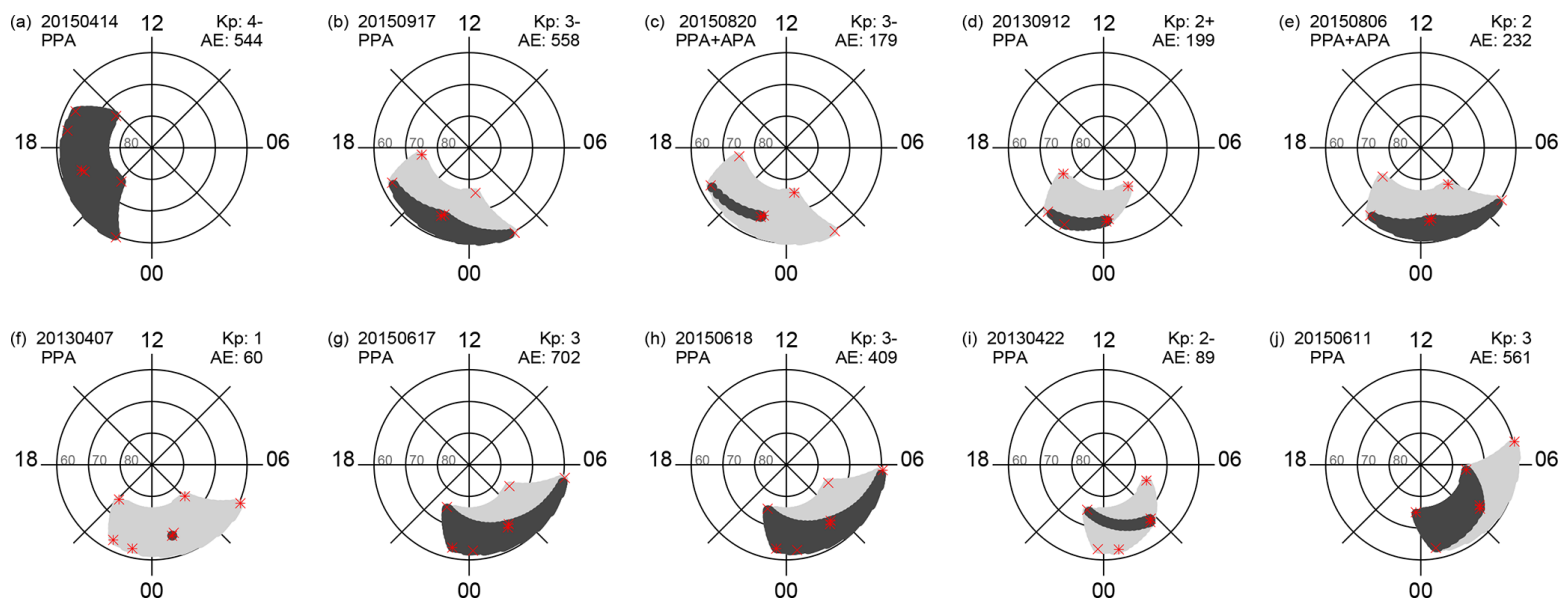

Figure 5. Same as Fig. 4 but for patchy pulsating aurora (PPA). 
bounded by all radars with available data, and then a portion of this area is shaded dark grey to show the region in which the attenuation was detected. To determine the perimeter of each region, we performed a linear interpolation between the magnetic latitude and MLT coordinates of adjacent stations, which produces the curved lines in the polar plots. The event onset times are slightly different for each radar. To focus on the presence/absence of attenuation events, we use the dark grey shading to represent the total area in which attenuation was observed during the event. The auroral electrojet (AE) index and the planetary $\mathrm{K}$-index $(\mathrm{Kp})$ at the event onset time are also shown, and we note that there is no obvious correlation between geomagnetic activity and the size of the EEP impact area. This highlights the need to move beyond the geomagnetic-index-based descriptions of EEP forcing used for long-term climate modelling, since it does not adequately capture the contribution from PsA-related EEP.

A total of two APA events and one PPA event were detected by all radars simultaneously (dark grey shading only). For these events, the EEP impact area extended over a minimum of $7 \mathrm{~h}$ of MLT and $16^{\circ}$ of magnetic latitude. For the remaining events, the latitude or MLT boundary of the EEP impact area can be identified. For example, APA events nos. 3 and 5 are confined to the $\sim 60-70^{\circ}$ CGM latitude range. There are also many events that do not extend over the entire observable MLT range, such as APA event no. 9 and PPA event no. 3. A total of five APA events and one PPA event were observed only at Syowa Station. For these events, we conclude that the EEP impact area is narrow in both latitudinal and longitudinal extent. Since the radar coverage is very sparse, we checked ASC data from Syowa Station to determine the spatial coverage of the optical PsAs for these events. For all events detected only by the Syowa Station radars, the latitudinal extent of the optical PsA was narrower than the camera field of view. We show an example of this in Fig. 6 for APA event no. 2, where the optical PsA covers about half of the north-south field of view. We found no examples in which the east-west extent of the optical PsA was smaller than the camera field of view.

The results presented in Figs. 4 and 5 show that the EEP impact area associated with PsA events can vary significantly. However, due to the limited number of events that met our data availability criteria, it is difficult to draw conclusions about the average EEP impact area based on these results. Therefore, we now use the observations from all 74 events to build a statistical description of the EEP impact area. These results are presented in Fig. 7 using a format similar to a correlation matrix. Each cell shows the percentage of optical PsA events that were accompanied by an attenuation signature from both radars corresponding to that cell. For example, $36 \%$ of the optical PsA events were accompanied by an attenuation signature from both the HAL and SPS radars simultaneously. The percentage occurrence for the ASC paired with each individual radar is also included in Fig. 7. The cells are colour coded according to these percent-

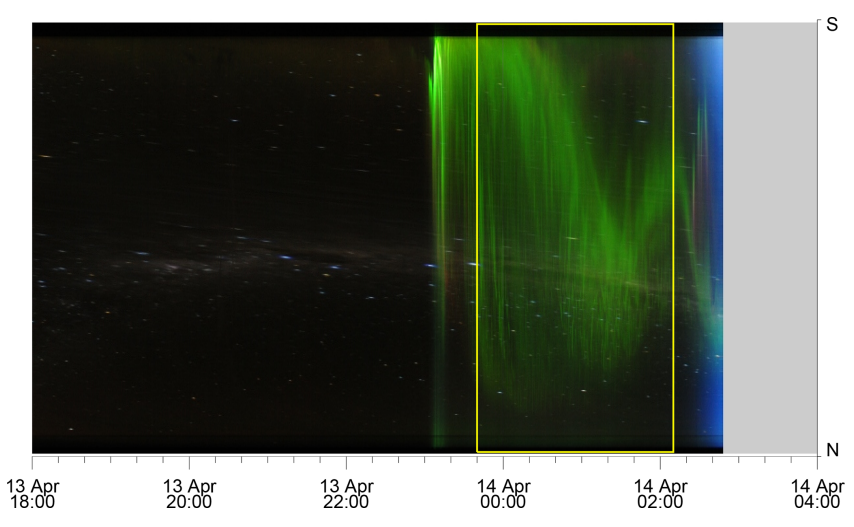

Figure 6. Magnetic north-south (N-S) keogram from the ASC at Syowa Station for the period 13-14 April 2013. The yellow rectangle indicates the time period during which the pulsating aurora was observed.

ages, and the numerical value is provided in each cell. The total number of events used to calculate the percentage is given in parentheses. The total number of events varies widely between radar pairs because there were many events for which data were not available from both radars simultaneously. The radars/ASC are sorted by magnetic longitude on the horizontal axis and magnetic latitude on the vertical axis, except for DCE which is placed to the far right/top of the plot. The geomagnetic coordinates for each instrument are shown below each three-letter radar/camera code. Cells with a dark blue outline identify instrument pairs that are separated by less than $5^{\circ}$ of magnetic latitude, which are useful for estimating the longitudinal extent of the EEP impact area at a particular latitude. Similarly, cells with a light blue outline identify radar pairs that are separated by less than $15^{\circ}$ of magnetic longitude and can be used to estimate the latitudinal extent of the EEP impact area.

We will first discuss the probability that each radar detects HF attenuation simultaneously with optical PsAs at Syowa Station. A total of $100 \%$ of the optical PsA events at Syowa Station were accompanied by HF attenuation at SYE and SYS. This is expected because these instruments have similar fields of view. The HAL radar, which is located at a similar magnetic latitude to Syowa Station, but $44^{\circ}$ to the west, detected HF attenuation with $75 \%$ probability. For radars near the poleward edge of the auroral oval, we see that $24 \%$ of the optical PsA events were accompanied by attenuation at $\mathrm{ZHO}\left(75^{\circ}\right.$ latitude), and this drops to just $10 \%$ at $80^{\circ}$ latitude (MCM radar). For the lowest magnetic latitude station, FIR, data were available for just four events, and the radar detected attenuation for only one of these events, so the $25 \%$ occurrence rate for this radar is unreliable.

The KER-HAL and SPS-ZHO radar pairs provide information about the MLT extent of the EEP impact area near the equatorward and poleward edges of the auroral oval, respectively. The KER and HAL radars, located at 59-62 latitude, 

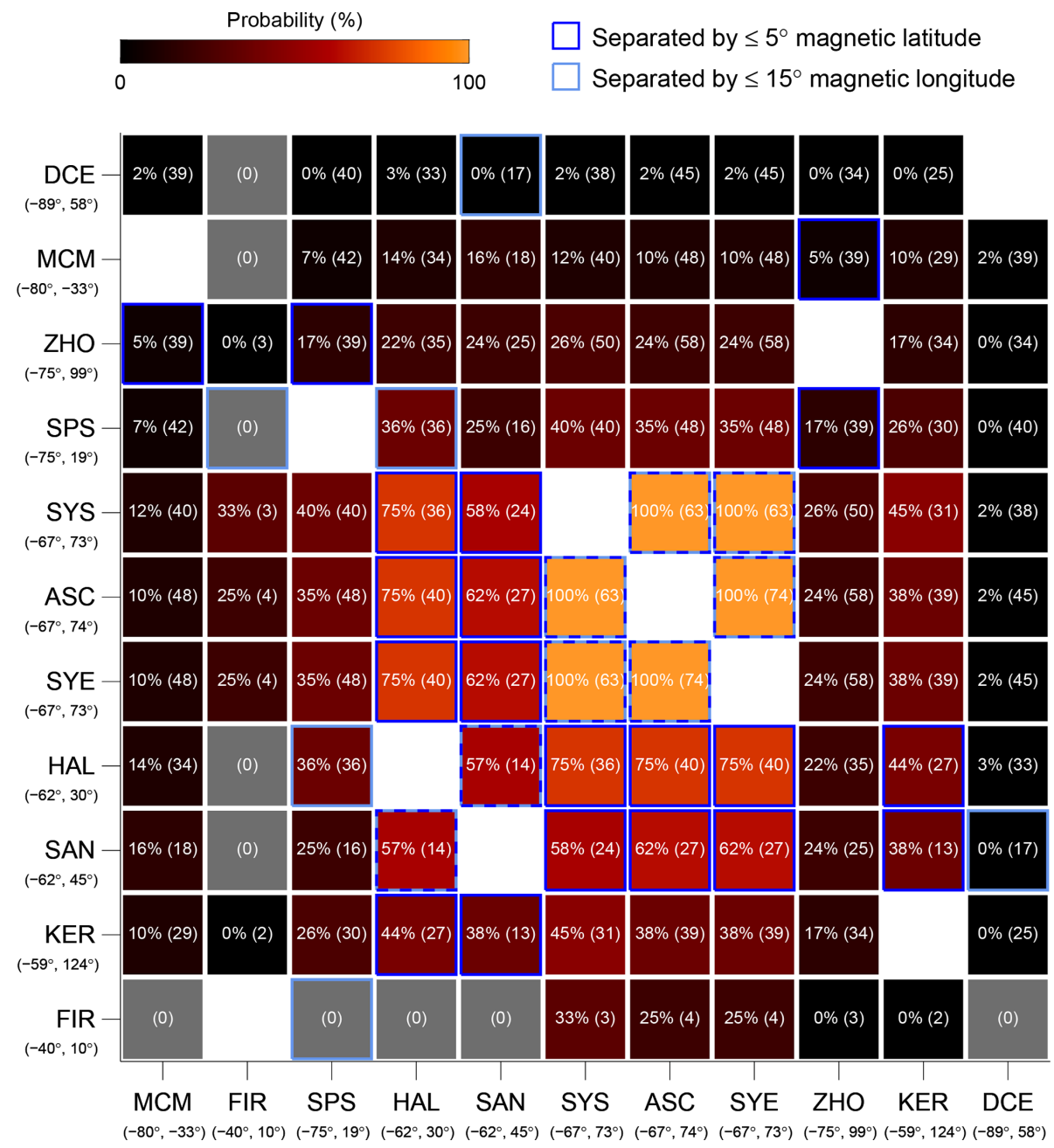

Figure 7. Probability of detecting HF radio attenuation for each pair of SuperDARN radars. In all cases, optical PsAs were also detected simultaneously by the ASC at Syowa Station. The white text shows the probabilities for each radar pair, and the number of events used to calculate these probabilities is given in parentheses. The probabilities for the ASC paired with each radar are also shown. The box shading is used to represent these probabilities visually. The corrected geomagnetic coordinates for each radar are given in parentheses below each three-letter station ID. The radars/ASC are sorted by magnetic longitude on the horizontal axis (except DCE) and by magnetic latitude on the vertical axis. Dark and light blue box outlines indicate radars with a similar magnetic latitude and magnetic longitude, respectively.

both detected attenuation for $44 \%$ of the PsA events. This radar pair is separated by $\sim 6 \mathrm{~h}$ of MLT. At the poleward edge of the auroral oval $\left(\sim 75^{\circ}\right), 17 \%$ of events were detected by both the SPS and ZHO radars, which have a $7 \mathrm{~h}$ MLT separation. We conclude from these results that the MLT extent of the EEP impact area is, on average, larger at the equatorward edge of the auroral oval.

The HAL-SPS radar pair provides information about the latitudinal extent of the EEP impact area to the west of our reference location at Syowa Station. This pair detected HF attenuation simultaneously with a probability of $36 \%$. East of the reference location, the ZHO-KER radar pair detected HF attenuation simultaneously with a probability of $17 \%$. The SPS-HAL and ZHO-KER pairs do not have the same latitudinal spacing, so it is not appropriate to compare the probabilities between these pairs. However, both results indicate that the latitudinal extent of the EEP impact area is less than $12^{\circ}$ for the majority of events.

\section{Discussion}

The results presented in this study provide some basic estimates of the EEP impact area during pulsating aurora events. This type of information is necessary for developing realistic inputs to atmospheric models that are used to study the impact of EEP on the middle atmospheric chemistry and the contribution of EEP forcing to natural climate variability. Our results show that $36 \%$ of PsA events extend over at least $12^{\circ}$ of magnetic latitude (SPS-HAL pair), and $\sim 60 \%-$ $75 \%$ extend over at least $4^{\circ}$ of magnetic latitude (SYE-SAN 
and SYE-HAL pairs). At the equatorward edge of the auroral oval, $44 \%$ of events have a magnetic local time extent greater than $7 \mathrm{~h}$ (KER-HAL pair). At the poleward edge, $17 \%$ of events cover this MLT range (ZHO-SPS pair).

Our study has demonstrated a novel application of the SuperDARN HF radars for estimating the spatial extent of the EEP impact area during pulsating aurora events. The use of SuperDARN radars for this purpose provides an advantage over optical instruments because the radar observations are not restricted by daylight or cloud cover. This significantly increases the availability of multi-point observations for our statistical study. However, the number of events used to determine the occurrence probabilities for each radar pair are still relatively low (see Fig. 7). For validation purposes, we used the ASC data from Syowa Station as a starting point for identifying PsA-related HF attenuation in the SuperDARN data, which limits the observation time to periods of dark, clear skies at Syowa Station. The four most important radars for estimating the EEP impact area in our study are KER, ZHO, SPS, and HAL. These radars provide observations from the equatorward and poleward edges of the Southern Hemisphere auroral oval over a wide longitudinal area. Unfortunately, the HAL radar ceased operations in 2015 , so it was not possible to extend the data set to include more recent events from that location. Although the data set for the other radars could potentially be expanded to include more events, it may be more fruitful to repeat this analysis using the North American SuperDARN radars. This would provide additional coverage from a larger number of radars and allow comparisons with optical PsA observations from the THEMIS ASCs and with riometer observations of cosmic noise absorption.

The Southern Hemisphere data were used in this study because they generally detect large amounts of backscatter on the nightside, which makes it straightforward to identify periods of reduced backscatter power. We speculate that the high echo occurrence for the Southern Hemisphere radars is due to the low operating frequencies used and more favourable geometry with the magnetic field for satisfying the aspect angle condition for ionospheric scatter detection. Also, the Southern Hemisphere radars generally operate at just one or two frequencies, making it easier to identify attenuation signatures in the background radio noise, which is frequency dependent. With an improved understanding of the background radio noise measured by SuperDARN radars, it may be possible to reliably identify HF attenuation events using only the background noise parameter. This would improve the suitability of the North American SuperDARN radars for estimating the EEP impact area.

Due to the limited number of events in our statistical study, some caution is required when interpreting the occurrence probabilities presented in Fig. 7. For most radar pairs, the occurrence probabilities were calculated based on 3040 events, so each event represents 2-4 percentage points. For the FIR and SAN radars, the uncertainties in the prob- abilities are much higher due to the low data availability. Based on the information presented in Fig. 3, we can determine which radars provide the most reliable information about PsA occurrence. These are the radars for which the large majority of events were either clearly observed or clearly not observed. This is the case for the two highestlatitude radars, MCM and DCE, so we conclude that the very low occurrence rates observed at 80 and $89^{\circ}$ are reliable. In contrast, there was significant uncertainty in identifying events for the KER, SAN, and HAL radars. The SAN radar in particular has a low total number of events and high uncertainties with respect to whether any attenuation occurred. Despite these uncertainties, it is apparent from Fig. 7 that the occurrence rates exhibit a smooth variation with the distance from Syowa Station, both in latitude and longitude.

To determine whether our results are realistic, we can make some simple comparisons to an earlier work. At the equatorward edge of the auroral oval, we found that $44 \%$ of events have a MLT extent greater than $7 \mathrm{~h}$ (KER-HAL pair). At the poleward edge, $17 \%$ of events cover this MLT range (ZHO-SPS pair). Optical observations by Grono and Donovan (2020) showed that APA occur over a wider MLT range at $\sim 65^{\circ}$ latitude compared to $\sim 75^{\circ}$ latitude. Although their study did not provide information about the instantaneous spatial coverage of optical PsAs, it is likely that the wider MLT range of APA observed at lower latitudes is due to a wider instantaneous spatial coverage of the events in their study and is therefore consistent with our results. It is also important to recognise that the latitudinal separation between Syowa Station and the ZHO-SPS and KER-HAL radar pairs might contribute to the different MLT extents observed at $\sim 60$ and $\sim 75^{\circ}$ latitude. The ZHO-SPS pair is located about $8^{\circ}$ poleward of Syowa Station, whereas the HAL and KER radars are about 5 and $8^{\circ}$ equatorward of Syowa Station, respectively. Therefore, with this study design it is difficult to decouple the effects of latitude and distance to the reference location when determining the MLT extent of PsAs.

Whatever the cause of these latitudinal differences in the EEP impact area, we can conclude from our results that the optical PsA event reported by Jones et al. (2013) is probably quite rare. For that event, optical PsAs were observed over $10 \mathrm{~h}$ of MLT, but our results indicate that a large majority of PsA events have an impact area covering less than $7 \mathrm{~h}$ of MLT. It is possible, however, that the EEP impact area is smaller than the spatial area over which optical PsAs are observed. This could be investigated further using the $\mathrm{Su}-$ perDARN radars and riometers in North America combined with simultaneous observations from the THEMIS all-sky cameras.

A key difference in our results compared to earlier work is the location of the poleward boundary of PsAs. Our results show that PsA-related attenuation frequently extends beyond $\sim 75^{\circ}$ latitude. This was determined using the SPS-SYE and ZHO-SYE radar pairs, which detected PsA-related attenuation with $35 \%$ and $24 \%$ probability, respectively. The MCM 
radar $\left(80^{\circ}\right.$ latitude) also detected attenuation with about $10 \%$ probability. This upper latitude boundary for PsAs is significantly poleward of the optical PsA boundary reported in earlier work. For example, Oguti et al. (1981) reported that optical PsAs are restricted to $\leq 70^{\circ}$ magnetic latitude, but that discrete aurora may occur up to $75^{\circ}$ latitude. However, optical PsAs have been reported over Svalbard at $75^{\circ}$ latitude (Kvifte and Pettersen, 1969), and Grono and Donovan (2020) reported PsAs up to about $74-75^{\circ}$ but the occurrence was very low.

Grono and Donovan (2020) also showed that the magnetic latitude range of PsAs depends on the PsA type, with APA occurring over the magnetic latitude range $56-75^{\circ}$ and PPA and PA restricted to slightly narrower ranges of 57-73 and $59-74^{\circ}$, respectively. They reported that the APA occurrence probability above about $74^{\circ}$ was $\lesssim 15 \%$ and zero for PPA and PA. In our data set, there are several PPA events for which HF attenuation was detected by the ZHO or SPS radars. This is particularly so for event nos. $1,7,8$, 9, and 10 in Fig. 5, which is half of the events shown in that figure. $\mathrm{Kp}$ and $\mathrm{AE}$ indices for these PPA events are higher than for the other PPA events, which might play a role in determining the size and location of the EEP impact area. Differences in the auroral oval location between the Northern and Southern hemispheres may contribute to the different latitudinal coverage results in this study compared to Grono and Donovan (2020). We also note that the PsA type classification was determined only at Syowa Station, and it is likely that other PsA types, and non-pulsating auroral emissions, were present elsewhere for many events. Although we have excluded polar cap absorption (PCA) from our event list, it is possible that very weak PCA caused by proton fluxes below the $10 \mathrm{~cm}^{-2} \mathrm{sr}^{-1} \mathrm{~s}^{-1}$ threshold may cause some detectable $\mathrm{HF}$ attenuation at above $\sim 75^{\circ}$ magnetic latitude. However, the timing of the absorption detected at these polar latitude radars matches well with the optical PsAs observed at Syowa Station. It therefore seems more likely that the polar latitude attenuation is caused by energetic electron precipitation that is related to the PsA activity occurring equatorward.

Since PsAs are often observed in the recovery phase of substorms, it is worth comparing our results with earlier studies of the spatial extent of substorm precipitation. For example, riometer observations by Berkey et al. (1974) showed that substorm precipitation extends over the magnetic latitude range $\sim 60-74^{\circ}$. This magnetic latitude range is similar to the optical results described above, except that PsAs tend to remain further equatorward until the morning MLT sector. Regarding the HF attenuation observed at latitudes above $75^{\circ}$, Cresswell-Moorcock et al. (2013) reported that there is an enhancement in the $>30 \mathrm{keV}$ electron fluxes at $L>15$ in the morning sector about $1-2 \mathrm{~h}$ after the substorm onset. This is likely to correspond to the substorm recovery phase when PsAs are commonly observed. Therefore, some of the very high-latitude EEP fluxes reported by CresswellMoorcock et al. (2013) are probably related to PsAs. The latitude extent of these morning sector substorm-related EEP fluxes matches well with our observations of HF attenuation at magnetic latitudes above $75^{\circ}$ in connection with PsAs at Syowa Station.

Based on the results described above, we can make a rough estimate of the average EEP impact area that could be used as input to an atmospheric model such as WACCM (Marsh et al., 2007; Verronen et al., 2016). As described above, the majority of events cover less than $7 \mathrm{~h}$ of MLT. From the SYE, SYS, KER, SAN, and HAL pair combinations shown in Fig. 7, we determine that roughly half of the PsA events have an instantaneous MLT coverage of at least $2-3 \mathrm{~h}$ at $\sim 65^{\circ}$ magnetic latitude. Therefore, the average MLT extent at this latitude is probably around $4-5 \mathrm{~h}$. The average MLT extent is much narrower at $\sim 75^{\circ}$ magnetic latitude, with the large majority $(65 \%-76 \%)$ of events covering less than $2-4 \mathrm{~h}$ simultaneously (SYE-SPS and SYE-ZHO pairs). PsA occurrence rates reach a maximum in the early morning sector, at about 04:00 MLT (Jones et al., 2011; Bland et al., 2019; Grono and Donovan, 2020), and this result could be used to centre the EEP impact area in a model PsA forcing. The average latitudinal extent of the EEP impact area is difficult to estimate due to the very sparse latitudinal coverage of the SuperDARN radars and the latitude dependence of PsA occurrence. We have determined that approximately one-third of the events cover $12^{\circ}$ of latitude to the west of Syowa Station (SPS-HAL pair), so the median latitudinal extent would be a few degrees narrower. By combining this result with the latitude-dependent optical PsA occurrence rates (Grono and Donovan, 2020, Fig. 5), one could reasonably assume that the average EEP impact area covers the magnetic latitude range of about $62-70^{\circ}$.

Since our event detection procedure is qualitative, we cannot draw conclusions about the magnitude of the D-region electron density enhancements. This may be possible in the future with improved baselining of the background noise parameter (e.g. Berngardt, 2020) and a better understanding of the sensitivity of SuperDARN radars to PsA-related EEP. For the purposes of atmospheric modelling, however, statistical EEP energy spectra from satellite observations (e.g. Tesema et al., 2020b) would probably provide a more accurate estimate the relative impact of different types of PsAs than what is possible with the SuperDARN radars.

\section{Conclusions}

The spatial extent of the EEP impact area during 74 pulsating aurora events has been estimated using observations of HF radio attenuation from 10 SuperDARN radars in Antarctica. We defined the EEP impact area as the horizontal region over which PsA-related EEP has sufficient energy to cause a detectable amount of HF attenuation in the D-region ionosphere. This represents the area over which PsA-related EEP may cause an atmospheric chemical response. For $75 \%$ of 
the events studied, the EEP impact area extended over at least $4^{\circ}$ of magnetic latitude, and $36 \%$ of events extended over at least $12^{\circ}$ of magnetic latitude. The MLT extent was found to be larger, on average, at lower latitudes compared to higher latitudes. Based on our results, and earlier work using optical data, we estimated the average EEP impact area for PsAs that could be used as input to an atmospheric model such as WACCM. This average EEP impact area extends from about $62-70^{\circ}$ magnetic latitude and covers about $4-5 \mathrm{~h}$ of MLT. We emphasise that the SuperDARN radars have sparse spatial coverage, and that the sample size used in our statistical study was relatively small, so these results provide only a rough estimate of the average EEP impact area.

Code availability. Software for reading and analysing SuperDARN data is available at https://doi.org/10.5281/zenodo.801458 (SuperDARN Data Analysis Working Group et al., 2021).

Data availability. The SuperDARN data were obtained from the British Antarctic Survey data mirror (https://www.bas.ac.uk/ project/superdarn; British Antarctic Survey, 2020). The all-sky camera data were provided by the National Institute of Polar Research, Japan (http://polaris.nipr.ac.jp/ acaurora/syowa_CDC_ QL/; National Institute of Polar Research, Japan, 2020). Geomagnetic activity indices were obtained from the GSFC/SPDF OMNIWeb interface (https://omniweb.gsfc.nasa.gov; NASA, 2020).

Author contributions. The SuperDARN data analysis was done by EB. NP provided the original PsA event list from Syowa Station, and FT performed the classification. All authors contributed to the discussion of the results and the writing of the paper.

Competing interests. The authors declare that they have no conflict of interest.

Special issue statement. This article is part of "Special Issue on the joint 19th International EISCAT Symposium and 46th Annual European Meeting on Atmospheric Studies by Optical Methods". It is a result of the 19th International EISCAT Symposium 2019 and 46th Annual European Meeting on Atmospheric Studies by Optical Methods, Oulu, Finland, 19-23 August 2019.

Acknowledgements. Emma Bland has been supported by the Research Council of Norway (NRC; grant no. 287427). Noora Partamies and Fasil Tesema have been supported by the NRC under CoE (grant no. 223252). The authors acknowledge the use of SuperDARN data. SuperDARN is a collection of radars funded by the national scientific funding agencies of Australia, Canada, China, France, Italy, Japan, Norway, South Africa, the United Kingdom, and the United States of America. We thank Hiroshi Miyaoka of the National Institute of Polar Research (NIPR), Japan, for provid- ing the data from the all-sky colour digital camera at Syowa Station. This camera is part of the science programme of the Japanese Antarctic Research Expedition and NIPR.

Financial support. This research has been supported by the Norges Forskningsråd (grant nos. 287427 and 223252).

Review statement. This paper was edited by Andrew J. Kavanagh and reviewed by two anonymous referees.

\section{References}

Berkey, F. T., Driatskiy, V. M., Henriksen, K., Hultqvist, B., Jelly, D. H., Shchuka, T. I., Theander, A., and Ylindemi, J.: A synoptic investigation of particle precipitation dynamics for 60 substorms in IQSY (1964-1965) and IASY (1969), Planet. Space Sci., 22, 255-307, https://doi.org/10.1016/0032-0633(74)90028-2, 1974.

Berngardt, O. I.: Noise level forecasts at $8-20 \mathrm{MHz}$ and their use for morphological studies of ionospheric absorption variations at EKB ISTP SB RAS radar, Adv. Space Res., 66, 278-291, https://doi.org/10.1016/j.asr.2020.04.005, 2020.

Berngardt, O. I., Ruohoniemi, J. M., Nishitani, N., Shepherd, S. G., Bristow, W. A., and Miller, E. S.: Attenuation of decameter wavelength sky noise during x-ray solar flares in 2013-2017 based on the observations of midlatitude HF radars, J. Atmos. Sol.-Terr. Phy., 173, 1-13, https://doi.org/10.1016/j.jastp.2018.03.022, 2018.

Bland, E. C., Heino, E., Kosch, M. J., and Partamies, N.: SuperDARN Radar-Derived HF Radio Attenuation During the September 2017 Solar Proton Events, Space Weather, 16, 14551469, https://doi.org/10.1029/2018SW001916, 2018.

Bland, E. C., Partamies, N., Heino, E., Yukimatu, A. S., and Miyaoka, H.: Energetic Electron Precipitation Occurrence Rates Determined Using the Syowa East SuperDARN Radar, J. Geophys. Res.-Space, 124, 6253-6265, https://doi.org/10.1029/2018JA026437, 2019.

British Antarctic Survey: Super Dual Auroral Radar Network, available at: https://www.bas.ac.uk/project/superdarn, last access: 1 June 2020.

Chakraborty, S., Ruohoniemi, J. M., Baker, J. B. H., and Nishitani, N.: Characterization of Short-Wave Fadeout seen in Daytime SuperDARN Ground Scatter Observations, Radio Sci., 53, 472-484, https://doi.org/10.1002/2017RS006488, 2018.

Chakraborty, S., Baker, J. B. H., Ruohoniemi, J. M., Kunduri, B., Nishitani, N., and Shepherd, S. G.: A Study of SuperDARN Response to Co-occurring Space Weather Phenomena, Space Weather, 17, 1351-1363, https://doi.org/10.1029/2019SW002179, 2019.

Chisham, G., Lester, M., Milan, S. E., Freeman, M. P., Bristow, W. A., Grocott, A., McWilliams, K. A., Ruohoniemi, J. M., Yeoman, T. K., Dyson, P. L., Greenwald, R. A., Kikuchi, T., Pinnock, M., Rash, J. P. S., Sato, N., Sofko, G. J., Villain, J. P., and Walker, A. D. M.: A decade of the Super Dual Auroral Radar Network (SuperDARN): Scientific achievements, new techniques and future directions, Surv. Geophys., 28, 33-109, https://doi.org/10.1007/s10712-007-9017-8, 2007. 
Cresswell-Moorcock, K., Rodger, C. J., Kero, A., Collier, A. B., Clilverd, M. A., Häggström, I., and Pitkänen, T.: A reexamination of latitudinal limits of substorm-produced energetic electron precipitation, J. Geophys. Res.-Space, 118, 6694-6705, https://doi.org/10.1002/jgra.50598, 2013.

Donovan, E., Mende, S., Jackel, B., Frey, H., Syrjäsuo, M., Voronkov, I. Trondsen, T., Peticolas, L., Angelopoulos, V., Harris, S., Greffen, M., and Connors, M.: The THEMIS all-sky imaging array - System design and initial results from the prototype imager, J. Atmos. Sol.-Terr. Phy., 68, 1472-1487, 2006.

Fang, X., Randall, C. E., Lummerzheim, D., Solomon, S. C., Mills, M. J., Marsh, D. R., Jackman, C. H., Wang, W., and Lu, G.: Electron impact ionization: A new parameterization for $100 \mathrm{eV}$ to $1 \mathrm{MeV}$ electrons, J. Geophys. Res.-Space, 113, A09311, https://doi.org/10.1029/2008JA013384, 2008.

Fiori, R. A. D., Koustov, A. V., Chakraborty, S., Ruohoniemi, J. M., Danskin, D. W., Boteler, D. H., and Shepherd, S. G.: Examining the potential of the Super Dual Auroral Radar Network for monitoring the space weather impact of solar X-ray flares, Space Weather, 16, 1348-1362, https://doi.org/10.1029/2018SW001905, 2018.

Greenwald, R. A., Baker, K. B., Dudeney, J. R., Pinnock, M., Jones, T. B., Thomas, E. C., Villain, J. P., Cerisier, J. C., Senior, C., Hanuise, C., Hunsucker, R. D., Sofko, G. J., Koehler, J., Nielsen, E., Pellinen, R., Walker, A. D. M., Sato, N., and Yamagishi, H.: DARN/SuperDARN: A Global View of the Dynamics of High-Latitude Convection, Space Sci. Rev., 71, 761-796, https://doi.org/10.1007/BF00751350, 1995.

Grono, E. and Donovan, E.: Differentiating diffuse auroras based on phenomenology, Ann. Geophys., 36, 891-898, https://doi.org/10.5194/angeo-36-891-2018, 2018.

Grono, E. and Donovan, E.: Constraining the Source Regions of Pulsating Auroras, Geophys. Res. Lett., 46, 10267-10273, https://doi.org/10.1029/2019GL084611, 2019.

Grono, E. and Donovan, E.: Surveying pulsating auroras, Ann. Geophys., 38, 1-8, https://doi.org/10.5194/angeo-38-1-2020, 2020.

Jones, S. L., Lessard, M. R., Rychert, K., Spanswick, E., and Donovan, E.: Large-scale aspects and temporal evolution of pulsating aurora, J. Geophys. Res.-Space, 116, A03214, https://doi.org/10.1029/2010JA015840, 2011.

Jones, S. L., Lessard, M. R., Rychert, K., Spanswick, E., Donovan, E., and Jaynes, A. N.: Persistent, widespread pulsating aurora: A case study, J. Geophys. Res.-Space, 118, 2998-3006, https://doi.org/10.1002/jgra.50301, 2013.

Juusola, L., Østgaard, N., Tanskanen, E., Partamies, N., and Snekvik, K.: Earthward plasma sheet flows during substorm phases, J. Geophys. Res.-Space, 116, A10228, https://doi.org/10.1029/2011JA016852, 2011.

Kasahara, S., Miyoshi, Y., Yokota, S., Mitani, T., Kasahara, Y., Matsuda, S., Kumamoto, A., Matsuoka, A., Kazama, Y., Frey, H. U., Angelopoulos, V., Kurita, S., Keika, K., Seki, K., and Shinohara, I.: Pulsating aurora from electron scattering by chorus waves, Nature, 554, 337-340, https://doi.org/10.1038/nature25505, 2018.

Kvifte, G. J. and Pettersen, H.: Morphology of the pulsating aurora, Planet. Space Sci., 17, 1599-1607, https://doi.org/10.1016/00320633(69)90148-2, 1969.

Lessard, M. R.: A review of pulsating aurora, Auroral phenomenology and magnetospheric processes: Earth and Other Planets, 197,
55-68, https://agupubs.onlinelibrary.wiley.com/doi/abs/10.1029/ 2011GM001187 (last access: 8 February 2021), 2012.

Marsh, D., Garcia, R., Kinnison, D., Boville, B., Sassi, F., Solomon, S., and Matthes, K.: Modeling the whole atmosphere response to solar cycle changes in radiative and geomagnetic forcing, J. Geophys. Res.-Atmos., 112, D23306, https://doi.org/10.1029/2006JD008306, 2007.

Milan, S. E., Jones, T. B., Robinson, T. R., Thomas, E. C., and Yeoman, T. K.: Interferometric evidence for the observation of ground backscatter originating behind the CUTLASS coherent HF radars, Ann. Geophys., 15, 29-39, https://doi.org/10.1007/s00585-997-0029-y, 1997.

Miyoshi, Y., Katoh, Y., Nishiyama, T., Sakanoi, T., Asamura, K., and Hirahara, M.: Time of flight analysis of pulsating aurora electrons, considering wave-particle interactions with propagating whistler mode waves, J. Geophys. Res.-Space, 115, A10312, https://doi.org/10.1029/2009JA015127, 2010.

Miyoshi, Y., Oyama, S., Saito, S., Kurita, S., Fujiwara, H., Kataoka, R., Ebihara, Y., Kletzing, C., Reeves, G., Santolik, O., Clilverd, M., Rodger, C. J., Turunen, E., and Tsuchiya, F.: Energetic electron precipitation associated with pulsating aurora: EISCAT and Van Allen Probe observations, J. Geophys. Res.-Space, 120, 2754-2766, https://doi.org/10.1002/2014JA020690, 2015.

NASA: GSFC/SPDF OMNIWeb interface, available at: https:// omniweb.gsfc.nasa.gov, last access: 1 June 2020.

National Institute of Polar Research, Japan: Syowa Color Digital Camera (CDC), available at: http://polaris.nipr.ac.jp/ acaurora/ syowa_CDC_QL/, last access: 1 June 2020.

Nishimura, Y., Lessard, M. R., Katoh, Y., Miyoshi, Y., Grono, E., Partamies, N., Sivadas, N., Hosokawa, K., Fukizawa, M., Samara, M., Michell, R. G., Kataoka, R., Sakanoi, T., Whiter, D. K., Oyama, S., Ogawa, Y., and Kurita, S.: Diffuse and pulsating aurora, Space Sci. Rev., 216, 1-38, https://doi.org/10.1007/s11214-019-0629-3, 2020.

Nishitani, N., Ruohoniemi, J. M., Lester, M., Baker, J. B. H., Koustov, A. V., Shepherd, S. G., Chisham, G., Hori, T., Thomas, E. G., Makarevich, R. A., Marchaudon, A., Ponomarenko, P., Wild, J. A., Milan, S. E., Bristow, W. A., Devlin, J., Miller, E., Greenwald, R. A., Ogawa, T., and Kikuchi, T.: Review of the accomplishments of mid-latitude Super Dual Auroral Radar Network (SuperDARN) HF radars, Prog. Earth Planet. Sc., 6, 1-57, https://doi.org/10.1186/s40645-019-0270-5, 2019.

Oguti, T., Kokubun, S., Hayashi, K., Tsuruda, K., Machida, S., Kitamura, T., Saka, O., and Watanabe, T.: Statistics of pulsating auroras on the basis of all-sky TV data from five stations. I. Occurrence frequency, Can. J. Phys., 59, 1150-1157, https://doi.org/10.1139/p81-152, 1981.

Partamies, N., Juusola, L., Tanskanen, E., and Kauristie, K.: Statistical properties of substorms during different storm and solar cycle phases, Ann. Geophys., 31, 349-358, https://doi.org/10.5194/angeo-31-349-2013, 2013.

Partamies, N., Whiter, D., Kadokura, A., Kauristie, K., Nesse Tyssøy, H., Massetti, S., Stauning, P., and Raita, T.: Occurrence and average behavior of pulsating aurora, J. Geophys. Res.Space, 122, 5606-5618, https://doi.org/10.1002/2017JA024039, 2017.

SuperDARN Data Analysis Working Group, Thomas, E. G., Schmidt, M. T., Bland, E. C., Burrell, A. G., Ponomarenko, P. V., Reimer, A. S., Sterne, K. T., and Walach, M.-T.: 
SuperDARN Radar Software Toolkit (RST) 4.5, Zenodo, https://doi.org/10.5281/zenodo.801458, 2021.

Tesema, F., Partamies, N., Nesse Tyss $\varnothing y$, H., Kero, A., and SmithJohnsen, C.: Observations of electron precipitation during pulsating aurora and its chemical impact, J. Geophys. Res.-Space, 125, e2019JA027713, https://doi.org/10.1029/2019JA027713, 2020a.

Tesema, F., Partamies, N., Nesse Tyssøy, H., and McKay, D.: Observations of precipitation energies during different types of pulsating aurora, Ann. Geophys., 38, 1191-1202, https://doi.org/10.5194/angeo-38-1191-2020, 2020 b.

Thorne, R. M., Ni, B., Tao, X., Horne, R. B., and Meredith, N. P.: Scattering by chorus waves as the dominant cause of diffuse auroral precipitation, Nature, 467, 943-946, https://doi.org/10.1038/nature09467, 2010.

Turunen, E., Verronen, P. T., Seppälä, A., Rodger, C. J., Cli1verd, M. A., Tamminen, J., Enell, C.-F., and Ulich, T.: Impact of different energies of precipitating particles on $\mathrm{NO}_{x}$ generation in the middle and upper atmosphere during geomagnetic storms, J. Atmos. Sol.-Terr. Phy., 71, 1176-1189, https://doi.org/10.1016/j.jastp.2008.07.005, 2009.

Turunen, E., Kero, A., Verronen, P. T., Miyoshi, Y., Oyama, S.-I., and Saito, S.: Mesospheric ozone destruction by high-energy electron precipitation associated with pulsating aurora, J. Geophys. Res.-Atmos., 121, 11852-11861, https://doi.org/10.1002/2016JD025015, 2016.

van de Kamp, M., Seppälä, A., Clilverd, M. A., Rodger, C. J., Verronen, P. T., and Whittaker, I. C.: A model providing longterm data sets of energetic electron precipitation during geomagnetic storms, J. Geophys. Res.-Atmos., 121, 12520-12540, https://doi.org/10.1002/2015JD024212, 2016.
Verronen, P. T., Seppälä, A., Clilverd, M. A., Rodger, C. J., Kyrölä, E., Enell, C.-F., Ulich, T., and Turunen, E.: Diurnal variation of ozone depletion during the October-November 2003 solar proton events, J. Geophys. Res.-Space, 110, A09S32, https://doi.org/10.1029/2004JA010932, 2005.

Verronen, P. T., Andersson, M. E., Marsh, D. R., Kovács, T., and Plane, J. M. C.: WACCM-D - Whole Atmosphere Community Climate Model with D-region ion chemistry, J. Adv. Model. Earth Sy., 8, 954-975, https://doi.org/10.1002/2015MS000592, 2016.

Watanabe, D. and Nishitani, N.: Study of ionospheric disturbances during solar flare events using the SuperDARN Hokkaido radar, Advances in Polar Science, 24, 12-18, https://doi.org/10.3724/SP.J.1085.2013.00012, 2013.

Yang, B., Donovan, E., Liang, J., and Spanswick, E.: A statistical study of the motion of pulsating aurora patches: using the THEMIS All-Sky Imager, Ann. Geophys., 35, 217-225, https://doi.org/10.5194/angeo-35-217-2017, 2017.

Yang, B., Spanswick, E., Liang, J., Grono, E., and Donovan, E.: Responses of Different Types of Pulsating Aurora in Cosmic Noise Absorption, Geophys. Res. Lett., 46, 5717-5724, https://doi.org/10.1029/2019GL083289, 2019. 